\title{
La iglesia de Santa María la Blanca de Sevilla: apreciaciones sobre su historia material
}

\author{
Juan Carlos Hernández Núñez \\ Universidad de Sevilla \\ jchmus@us.es
}

RESUMEN: Se dan a conocer los resultados de la investigación efectuada entre 2014 y 2015, durante las obras de restauración de las yeserías y pinturas que decoran el interior de la iglesia de Santa María la Blanca. Los nuevos datos han servido para ampliar el conocimiento sobre el origen y la historia de este templo sevillano.

PALABRAS CLAVE: Mezquita; Sinagoga; Restauración; Inmaculada Concepción; Justino de Neve; Papa Alejandro VII.

\section{The Church of Santa María la Blanca in Sevilla: Appreciations of its Material History}

ABSTRACT: The results of the research, carried out between 2014 and 2015, during the restoration works of the plasterwork and paintings that decorate the interior of the church of Santa María la Blanca, are disclosed. The information have served to clarify some of the existing gaps regarding the origin and history of this Seville temple.

KEYWORDS: Mosque; Synagogue; Immaculate Conception; Justino de Neve; Pope Alejandro VII.

Recibido: 5 de diciembre de 2020 / Aceptado: 5 de mayo de 2021.

En las últimas décadas el interés por la iglesia sevillana de Santa María de las Nieves, vulgo «la Blanca», ha hecho posible que en un corto espacio de tiempo hayan visto la luz un número estimable de publicaciones dedicadas a la historia del edificio. Ello ha sido posible gracias a las labores de restauración del inmueble desde el año 2000 y a la revalorización, en 2012, de la figura del canónigo de la catedral Justino de Neve, promotor de la renovación del templo a mediados del siglo XVII'. El poco espacio de tiempo transcurrido entre ellas no ha permitido contrastar ni verificar las diferentes hipótesis que se planteaban en estos trabajos, lo que menoscabó el conocimiento del edificio y de su historia. No es objeto del presente estudio realizar un compendio de lo ya conocido, sino compaginar las diferentes hipótesis aparecidas y dar a conocer los datos localizados en la investigación que se efectuó en paralelo a la restauración de las yeserías y pinturas que adornan el templo, intentando aportar un poco de claridad a la historia material del actual edificio [1].

Para Gil Delgado, arquitecto que dirigió la restauración arquitectónica y los estudios arqueológicos, entre los años 2010 y 2012, existieron dos edificios consecutivos en el tiempo y de diferentes dimensiones². El primero sería la mezquita, una pequeña construcción con el patio o sahn, que integraba las modernas oficinas del templo y con accesos en sus lados menores, uno hacia la calle de Santa María la Blanca, donde sitúa el alminar, y otro en el muro frontero, en un callejón que rodeaba la manzana hasta el siglo XVIII y del que aún subsisten algunos espacios. La sala de oración o haram era de planta cuadrada, ocupando los cuatro primeros tramos de las naves actuales, con el muro de la quibla en paralelo al actual de la epístola. Se compartimentaba en tres crujías perpendiculares a la quibla, con arcos de herradura sobre columnas de acarreo. Tenía un solo acceso desde el sahn, un arco de medio punto peraltado realizado con sillares, hoy conservado en el muro

Cómo citar este artículo: HERNÁNDEZ NÚÑEZ, Juan Carlos, "La iglesia de Santa María la Blanca de Sevilla: apreciaciones sobre su historia material», Boletín de Arte-UMA, n. ${ }^{\circ}$ 42, Departamento de Historia del Arte, Universidad de Málaga, 2021, pp. 97-108, ISSN: 0211-8483, e-ISSN: 2695-415X, DOI: http://dx.doi.org/10.24310/BoLArte.2021.vi42.11139 


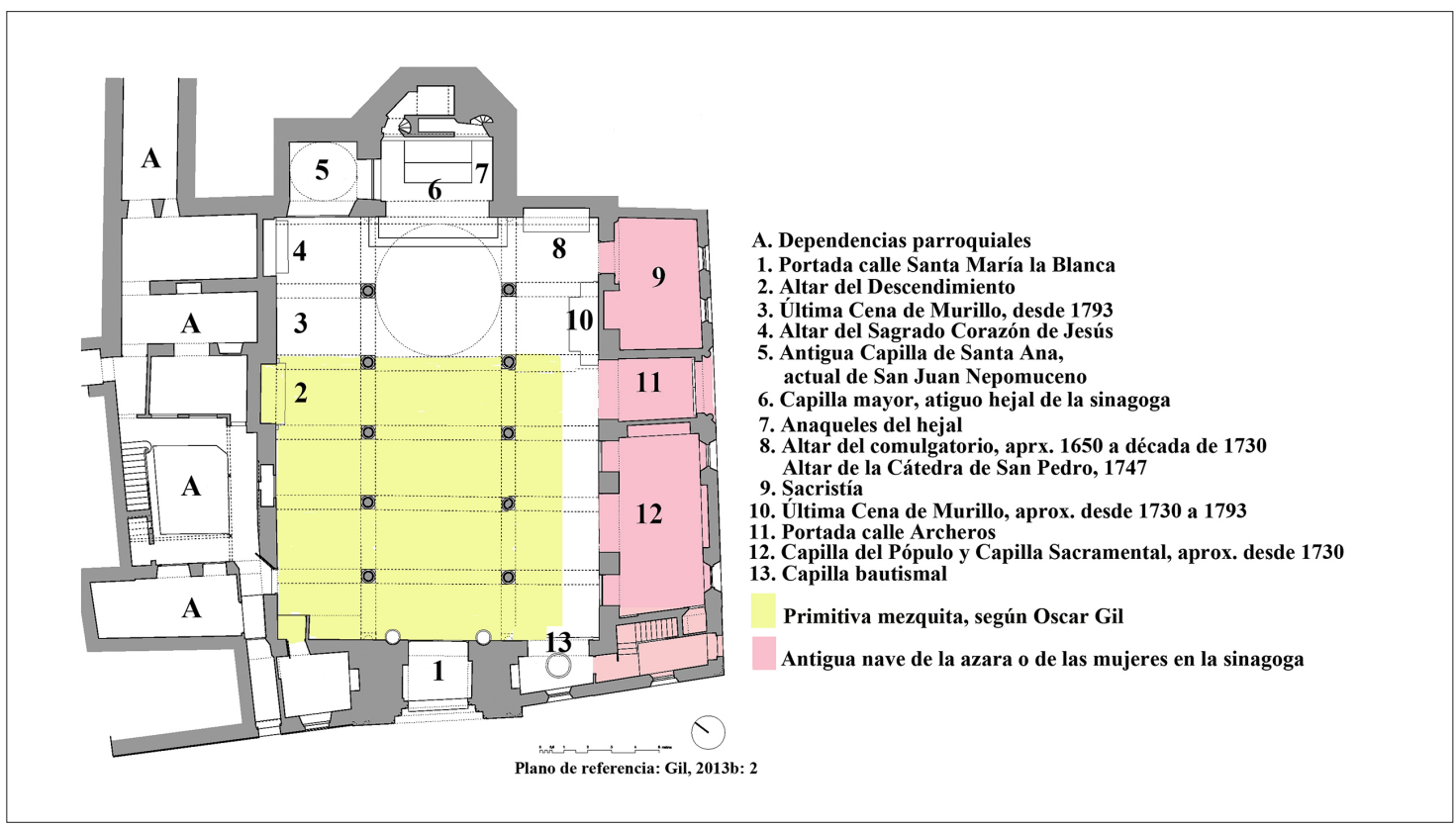

1. Planta de Santa María la Blanca

sur del patio, que le permite datar el edificio en los siglos $X_{0}$ XI. Conquistada la ciudad por san Fernando, se entregó a la comunidad judía para convertirla en sinagoga, ampliándose a las dimensiones actuales, tras el terremoto de $1356^{3}$. La sinagoga quedó divida en tres naves uniformes, orientadas hacia el noroeste, y articuladas en seis tramos, con el hejal en la cabecera de la central, coincidiendo hoy con la capilla mayor. Confirma este uso la aparición de cuatro hornacinas en su pared meridional, para la custodia de los objetos rituales. En este momento se construyeron los arcos ciegos de herradura con saeteras de ventilación, aparecidos sobre la arquería de la nave central [2] ${ }^{4}$.

Sin embargo Cómez en su monografía sobre las sinagogas sevillanas, al tratar de Santa María la Blanca, desmonta la hipótesis anterior, aludiendo ser un error muy común de arquitectos y arqueólogos el «tomar una parte por el todo", al no analizarlos en un contexto general y sin tener en consideración otras evidencias (2015: 109-123). Para el historiador mezquita, sinagoga e iglesia son un único edificio de idénticas dimensiones y configuración. Construido en época del emirato, entre los siglos VII y IX, su aspecto sería muy parecido al de las mezquitas aljamas de Córdoba y de Ibn Adabbas de Sevilla. Se caracterizaría por el empleo de arcos de herradura sobre columnas de acarreo, para su distribución interior, tres naves de seis tramos paralelas al muro de la quibla, y para sus accesos al patio, los arcos aparecidos en el muro norte del templo, que según Gil se abrieron en época cristiana para alojar altares o servir de acceso al patio o a otras dependencias (2013a: 94-96). Este tipo de arco también fue utilizado en las saeteras de ventilación y en el acceso de la calle Archeros, conservando aún sus columnas y capiteles, y que Falcón fecha en 1625 (2012: 63; 2015: 68). Como sugieren Gil y Falcón, de haberse construido la mezquita entre los siglos XI y XII, los arcos de herradura descansarían sobre pilares de ladrillos, como sucede en la antigua mezquita almohade de Cuatrovitas en Bollullos de la Mitación.

Siguiendo a Cómez, tampoco tiene sentido que Alfonso X, de las tres mezquitas cedidas a los judíos en 1252 -los actuales templos de Santa María la Blanca, San Bartolomé y Santa Cruz- eligiera la menor para convertirla en la sinagoga mayor. Y, más aún, cuando una transformación de tal envergadura, como proponen Gil y Falcón, estaba expresamente prohibida por las leyes de las Siete Partidas, además de tenerse que realizar en un ambiente hostil, como el que ya existía en Sevilla hacia 1370, de clara intransigencia anti- 


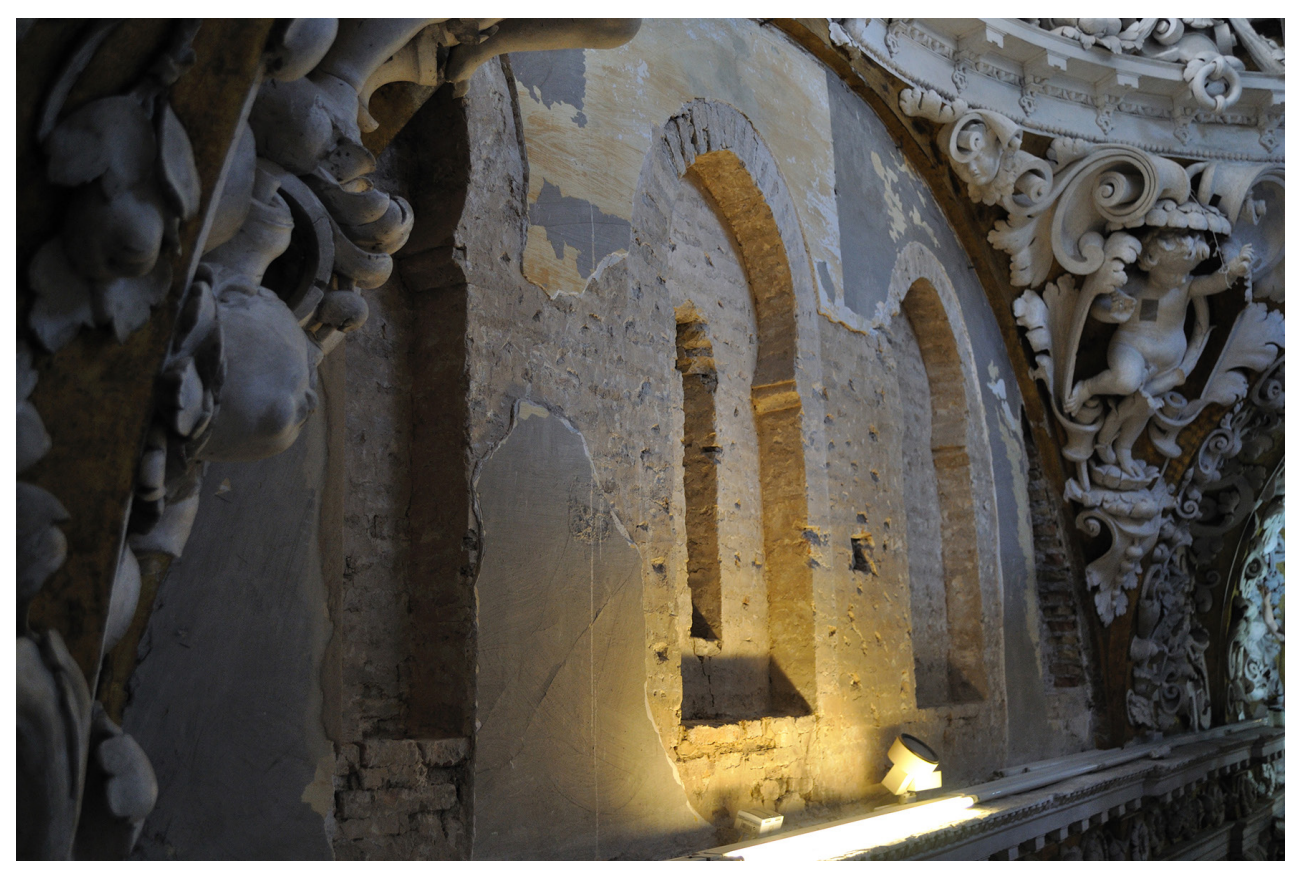

2. Arcos de herradura con saeteras de ventilación. Crucero

semita (Corral, 2014: 61-75). Cómez propone que las únicas obras que se realizarían en la antigua mezquita solo afectarían al cambio de culto. Según los preceptos hebraicos, se modificaría la orientación del edificio, hacia oriente, colocando el hejal en la cabecera de la nave central, y habilitándose dos entradas en ángulo recto, respecto al eje principal. Una para los hombres, en el patio, realzándose su arco con cantería y cerrando el resto de la arquería, y otra para las mujeres, la de la calle Archeros, que comunicaba con la nave de la azara o de las mujeres. Ambos arcos posiblemente seguirían siendo de herradura, si bien en el siglo XVI se transformarían en peraltados, al mutilar sus arranques (Cómez, 2015: 121). Al convertirse el edificio en iglesia cristiana en 1391, tras la revuelta antijudía, las únicas obras que se ejecutaron fueron la construcción de la portada principal con la espadaña ${ }^{5}$ a los pies de la nave central, dando así primacía al eje de la nueva capilla mayor, y la antigua capilla de santa Ana, hoy de san Juan Nepomuceno, en la cabecera de la nave del evangelio ${ }^{6}$ [3] y [4].

A lo largo de las centurias siguientes se emprenderían diferentes trabajos de reparación y mantenimiento en un edificio que cada día, debido a su antigüedad, presentaría más problemas. Se desconoce el alcance de las mismas, ya que la documentación localizada en diferentes archivos comienza en torno a 16257. Ese mismo año, en el cabildo de 11 de julio se lee la petición de los parroquianos de abrir una puerta a la iglesia, en la calle Archeros, por una casa propiedad de la fábrica de la catedral. Tres días más tarde, se concedía el permiso, con el requisito de que la obra fuera sufragada por los vecinos, no pudiéndose iniciar hasta no estar su importe en las arcas de la catedral ${ }^{8}$. En dicha noticia se basa Falcón para fechar su construcción (1998: 118), aunque, de haberse realizado en este momento su fisonomía sería distinta, más acorde con los gustos del momento. Retomando la hipótesis de Cómez (2015: 117-118, 122), en un momento de crisis económica, durante el siglo XV, se desgajaría del templo la nave de la azara de la sinagoga, dividiéndose en pequeños espacios que pudieron ser alquilados como casas o negocios, incrementándose así los recursos económicos del templo. Estos espacios, continuamente transformados entre 1640 y 1732, tenían doble altura, utilizando la Hermandad del Pópulo la inferior para su capilla y el piso alto para dependencias, almacenes e incluso viviendas ${ }^{9}$. De todas formas, la obra de 1625 tuvo que consistir simplemente en reabrir el antiguo acceso al edificio, dejando intacta su portada original [5]. 


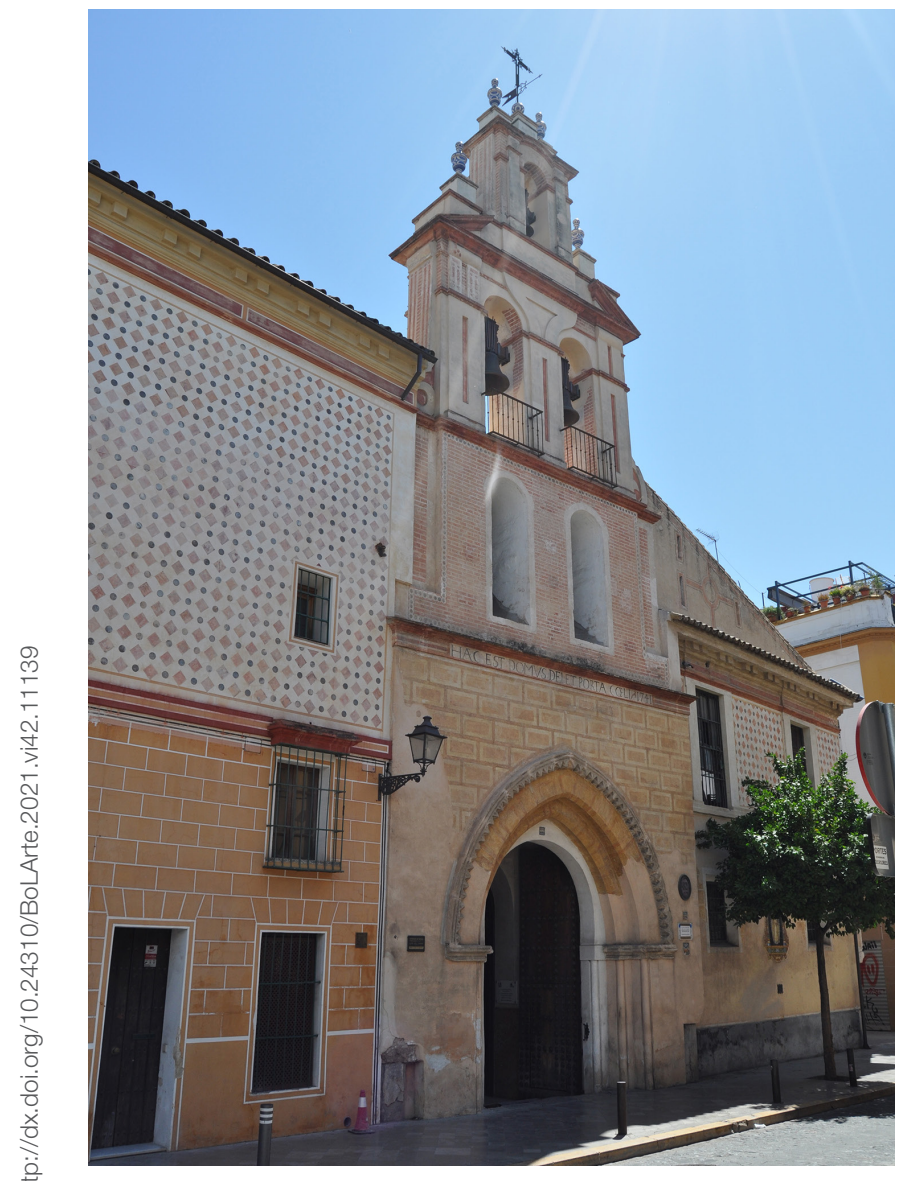

3. Fachada principal
En los años siguientes, al ser la documentación más abundante, se conocen mejor los reparos del templo. Entre los años de 1633 y 1635, aparece Pedro Sánchez Falconete, al que se le denomina "maestro mayor de la iglesia", refiriéndose a su cargo en la catedral, tasando las obras en el templo y posiblemente proyectándolas, por lo que su intervención en el edificio habría que adelantarla casi una década $^{10}$. En diciembre del primer año, cobró 12 reales por evaluar las obras que se debían realizar en la casa del cura; en marzo del año siguiente, 24, y las que se hicieron en 1635 las evaluó en 7.484 maravedíes. En general, estas consistían en la reparación de los tejados y sustitución de vigas y tablas, contratándose para ello a diferentes maestros albañiles, Juan de San Pedro en 1633, Alonso Núñez en 1640, Luis García en 1657 y Sebastián Pérez y Pedro del Valle en $1660^{11}$. Otro tipo de reparaciones, también constantes a lo largo del tiempo, son las provocadas por las humedades que dañaban las paredes y ocasionaba la caída de los zócalos de azulejos. En 1633 el encargado de repararlos fue el albañil Gaspar Pérez; en 1636, además de los desconchados, se intervino en los capiteles de las columnas y en 1638 en los propios soportes ${ }^{12}$. Además, en 1633 se hundió la "escalera de la torre y caracol», siendo de nuevo construida por Juan de San Pedro y, al año siguiente, se aderezó la de subida al coro, por encontrarse muy deteriorada ${ }^{13}$.

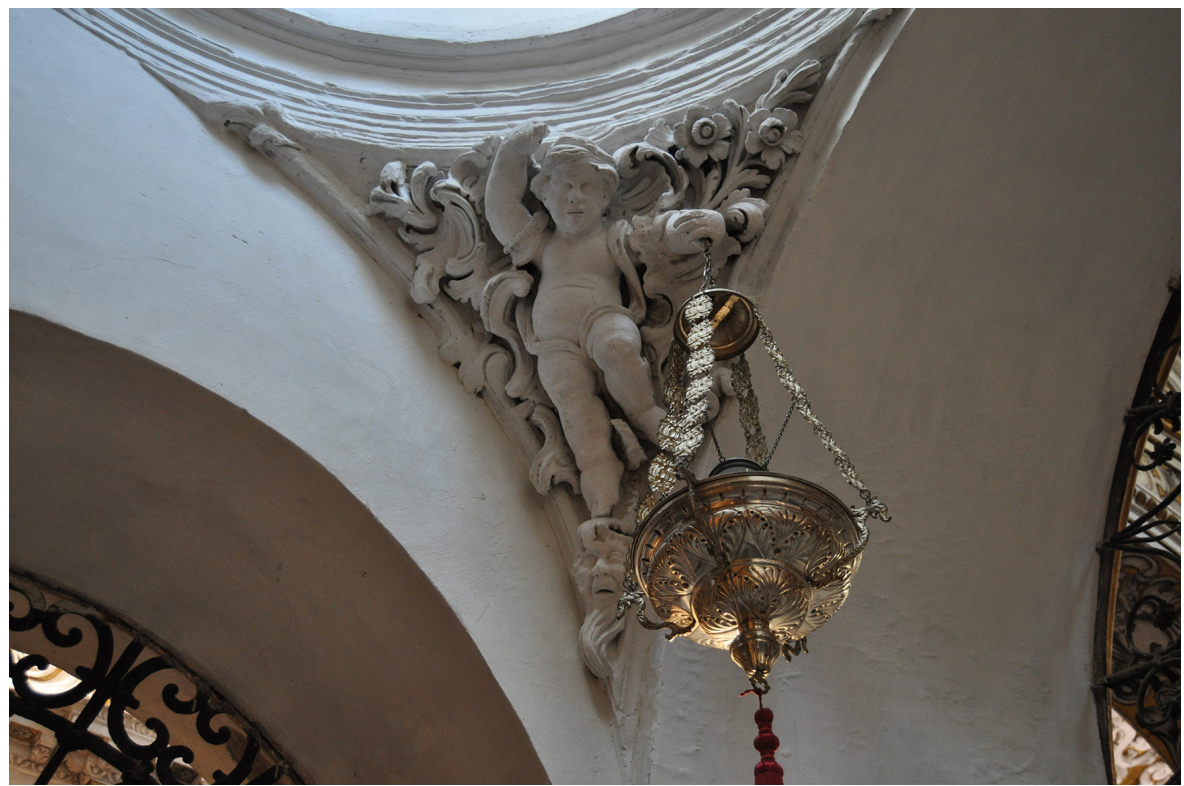

4. Capilla de San Juan

Nepomuceno. Yeserías de las pechinas. Hacia 1760 
Por las mismas fechas también se añaden nuevas construcciones al templo, las capillas del Bautismo (Falcón, 2015: 74) y la del Pópulo, conocida la última, desde mediados del XVIII, como capilla Sacramental. En 1642 fue la Hermandad del Populo la que solicitó la construcción de una capilla bautismal al Cabildo Catedral, concediéndole el permiso el 11 de julio y una ayuda de 1.500 reales $^{14}$. La información sobre la misma es bastante parca, desconociéndose si realmente se trataba de una edificación de nueva planta o, simplemente, de una reedificación o ampliación de la antigua. De esta, la única noticia localizada es su cierre, en 1566, con una reja de madera de balaustres torneados y asentada sobre «un poyo y escalones», por lo que evidencia su existencia ya en el siglo XVI ${ }^{15}$. La nueva capilla bautismal sería la que actualmente se conserva, situada a los pies de la nave de la epístola y que Cruz atribuyó a Falconete ${ }^{16}$. Su reja se colocó en $1751^{17}$.

Uno de los espacios más controvertidos y peor entendidos de la iglesia es el de la antigua capilla Sacramental, que simplemente era un altar conocido con el nombre del Comulgatorio, en el testero de la nave de la epístola, rodeado de una baranda. Sin embargo, para Falcón era un espacio situado en la cabecera de esta nave, con dos accesos, hacia la propia nave y a la capilla mayor, y que a mediados del siglo XIX, fue separado del templo y anexionado a la casa contigua (2015: 98; 2017: 96). En realidad, en su fisonomía, la confunde con la antigua capilla de Santa Ana, hoy de san Juan Nepomuceno, en el testero de la nave del evangelio, que tiene dos ingresos, y en la que la Hermandad Sacramental tuvo su altar en 1640 (2012: 61-71; 2013a: $307,312,314)$. De haber existido tal espacio en la cabecera de la epístola, hoy no existirían los anaqueles del hejal de la antigua sinagoga, pues habrían sido destruidos al hacerse la comunicación con el presbiterio ${ }^{18}$. Siguiendo a Falcón dicha capilla fue construida en el solar de una casa que «sirve de taberna» por Diego Gómez entre 1640 y 1650, edificándose sobre ella diferentes dependencias (1988: 120; 2013a: 309; 2015: 40-41, 72-73). Además, señala que tiene otro acceso que se abría al vestíbulo de la calle Archeros, donde también estaba la puerta de la sacristía. Tales características identifican este espacio con la antigua capilla del Pópulo, que es el único que presenta su techo plano para dar cabida a una segunda planta y linda con la entrada de Archeros ${ }^{19}$. Tal confusión, por parte de Falcón, puede ser debida a que ambas

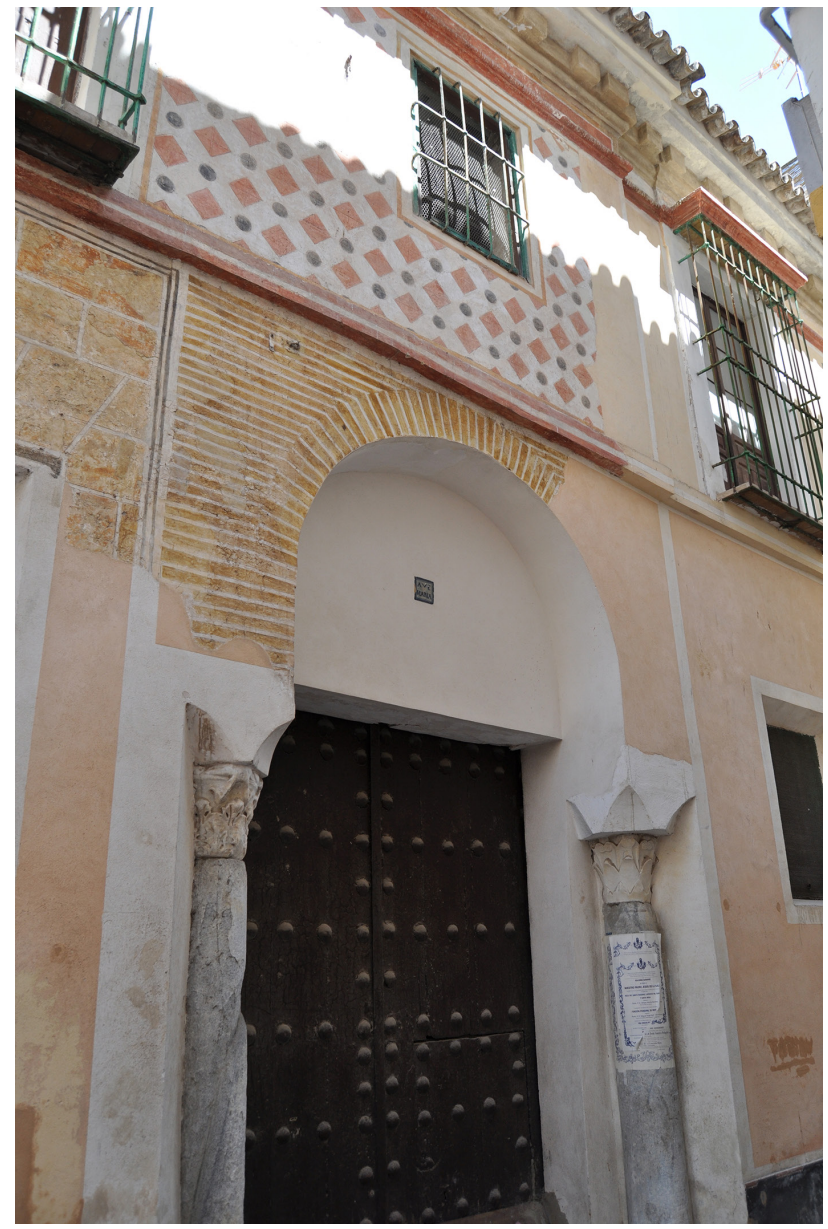

5. Portada de la calle Archeros

hermandades, la Sacramental y la del Pópulo, se unieron en 1672. Y que desde la década de 1730, compartieron el mismo espacio tras ceder el altar del Comulgatorio a la Hermandad de los Sacerdotes de la Cátedra de San Pedro. Con motivo de dicho traslado, la capilla fue reformada, adquiriendo el aspecto que hoy tiene, siendo estrenada en 1758 (1988: 120; 2015: 41,72) [6].

Según el acta de fusión de ambas hermandades, la Sacramental nunca llegó a tener capilla propia, solamente el referido altar del Comulgatorio, que Torre Farfán, en 1666, ya lo sitúa en el testero de la epístola (1666: 5v), sin que se conozca la fecha exacta de su traslado desde la capilla de Santa Ana. Quizás esto pudo estar relacionado con la donación del canónigo Mateo Coello de Vicuña del cuadro de Murillo de La Última Cena, en 1650, que desde el 30 de no- 


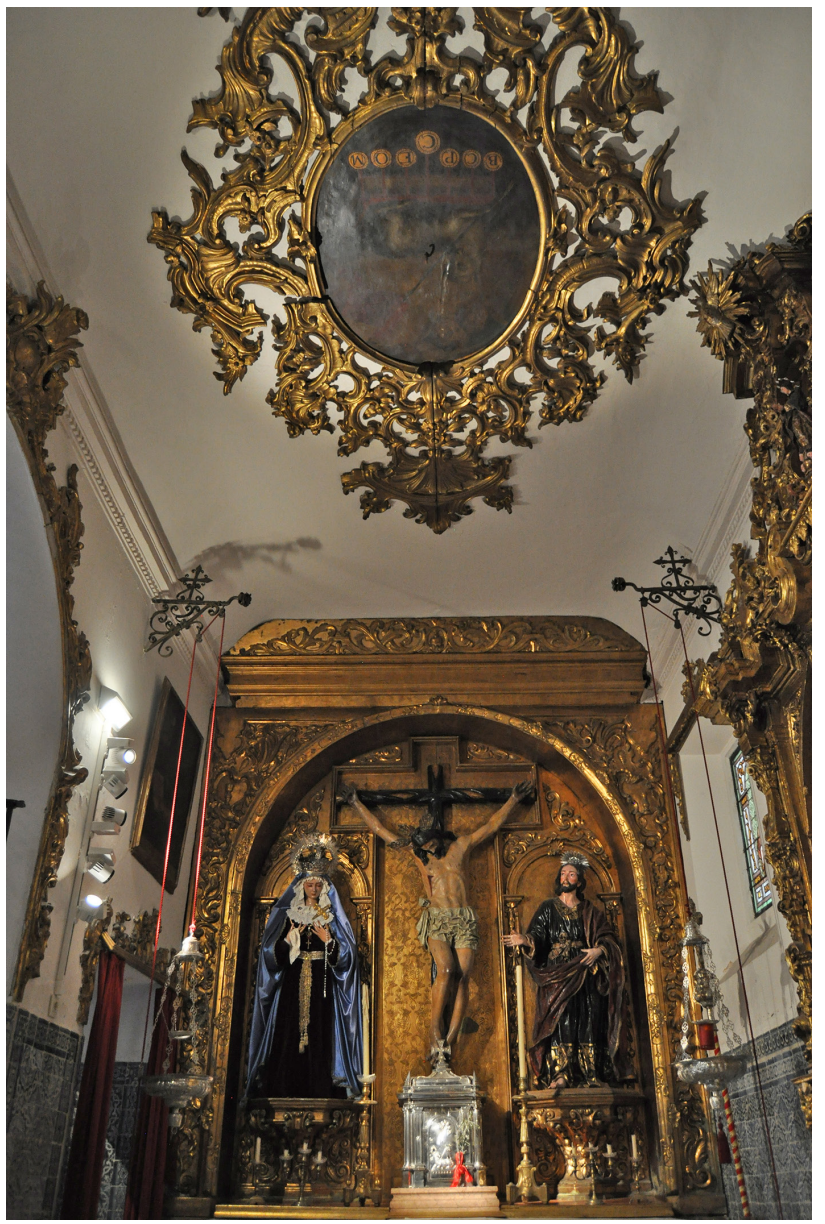

6. Capilla Sacramental

viembre de ese año presidía el altar ${ }^{20}$. Se ignora si este se colocó en el altar de la capilla de Santa Ana o, si por sus dimensiones, cosa más lógica, se tuvo que habilitar un nuevo espacio, pasando a la cabecera de la epístola. Al colocarse en el nuevo emplazamiento, se completó el altar con pinturas murales con la representación de las Virtudes, los dones del Espíritu Santo que se incrementan con la Eucaristía. De estas figuras solo se han conservado dos, la Fortaleza y la Caridad, que han sido descubiertas en el luneto durante la restauración del 2015. Según Falcón, tuvieron que ser realizadas entre 1650 y 1655 por el pintor Alonso Pérez (2017: 99). Con ellas puede estar relacionado el pago de 100 ducados que en 1655 se le entrega «a Pedro Martínez, mayordomo de la fábrica del Santísimo Sacramento, por los mismos que montó la pintura y demás aderezos de albañilería que se hizo en el remate de todas las paredes de la iglesia ${ }^{21}$. Cinco años más tarde, fueron ocultadas por la nueva decoración del templo y por el cuadro de La Fe, de Murillo, que se colocó sobre la Última Cena, quedando ambas pinturas unidas simbólicamente por la leyenda que aparece en el primero, «los amó hasta el extremo", y que san Juan en su evangelio cita antes de la cena pascual (Hernández y Morales, 2020). El altar continuó en el mismo lugar hasta la década de 1730 que se trasladó a la capilla del Pópulo y su espacio cedido a la Hermandad de los Sacerdotes, estrenando en 1747 su retablo de la Cátedra de san Pedro (Falcón, 2015: 111) [7]. En el nuevo emplazamiento, al tener la capilla el techo plano, no había suficiente altura para albergar el cuadro de Murillo, por lo que se colocaría donde hoy se encuentra el retablo de la Santísima Trinidad, por ser el único espacio disponible en esta nave para un cuadro de tal tamaño. Alí ya se encontraría en 1734, cuando los cofrades deciden su venta ${ }^{22}$, operación fallida que se volverá a repetir sin éxito en 1757, siendo tasado por Andrés Rubira, Domingo Martínez y Bernardo Lorente German, en 1000 pesos y 28 cuartos (Falcón, 2012: 68; 2015: 99; Núñez y otros, 2000: 109). En este lugar lo vio Ponz, en el último tercio del siglo XVIII (1786/1988: 83), permaneciendo hasta 1793, año en el que se colocó el retablo de la Trinidad. De ahí, fue llevado a la nave del evangelio, entre los retablos del Descendimiento y el actual del Sagrado Corazón ${ }^{23}$, donde lo contempló González de León en 1844 (1844/1973: 105).

El 16 de enero de 1662 se recibió en Sevilla el Breve de Alejandro VII Sollicitudo omnium Eccleasiarum en el que se aprobaba el culto a la Inmaculada Concepción de María. El júbilo que causó entre los capitulares fue enorme, estableciéndose una serie de festejos, del 5 al 8 de febrero, con luminarias y fuegos artificiales en la Giralda. En este ambiente de alegría, los feligreses de Santa María la Blanca se animaron a reformar el edificio. El 19 de junio, Justino de Neve presentaba ante el Cabildo la propuesta que fue aprobada, si bien la obra no comenzaría hasta reunir el dinero necesario ${ }^{24}$. Neve, encargado de dirigir la renovación del templo, concertó el 8 de junio su remodelación con el maestro albañil Juan González, según las trazas de este último. Las obras consistieron en la construcción de un falso crucero, cubierto con media naranja, y una bóveda de cañón en la nave central. Tales operaciones conllevaron el desmontaje de la estructura del tejado y la elevación del castillete del crucero. Comenza- 
7. Altar del Comulgatorio: A. Aprox: 1650 a 1665. Restos de la decoración realizada en 1655. B. Entre 1666 y década de 1730. C. Entre 1747 y

1810. Tras la instalación del altar de la Cátedra de San Pedro (fotomontaje: basado en la ilustración de Valdivieso y Martínez del Valle, 2012: 161)
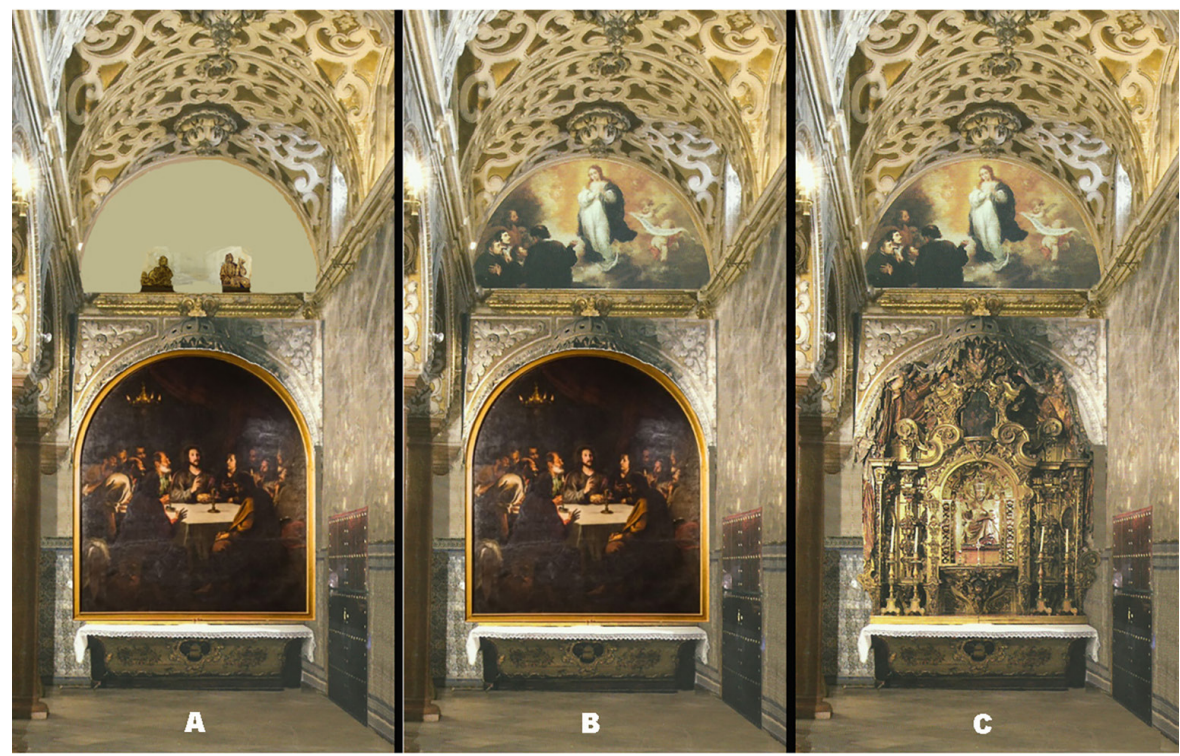

da la obra, aparecieron problemas en los antiguos soportes por lo que se resolvió reemplazarlos, contratándose, el 23 de julio de 1663, con Gabriel de Mena, la realización de 10 columnas con sus basas y capiteles de jaspe rojo, procedentes de las canteras de Antequera (Arenillas, 2005: 177; Falcón, 2015: 81-82) [8]

Terminadas las obras se iniciaron las tareas de ornamentación de las bóvedas y las paredes. El programa deco- rativo fue ideado por Neve contando con la ayuda de Murillo, a quien Falcón injustificadamente le atribuye las pinturas murales, en colaboración con el pintor Alonso Pérez (2012: 61; 2013b; 2015: 91-97). Dichas pinturas, que cubrirían las paredes y arcos formeros, se basan en la repetición de motivos aplantillados de cogollos, roleos vegetales entre las que se situaban querubines y putti, que recuerdan los trabajos de Jean Le Pautre. Junto a estas, en cartelas y cartuchos con
8. Decoración de yeserías y pinturas murales

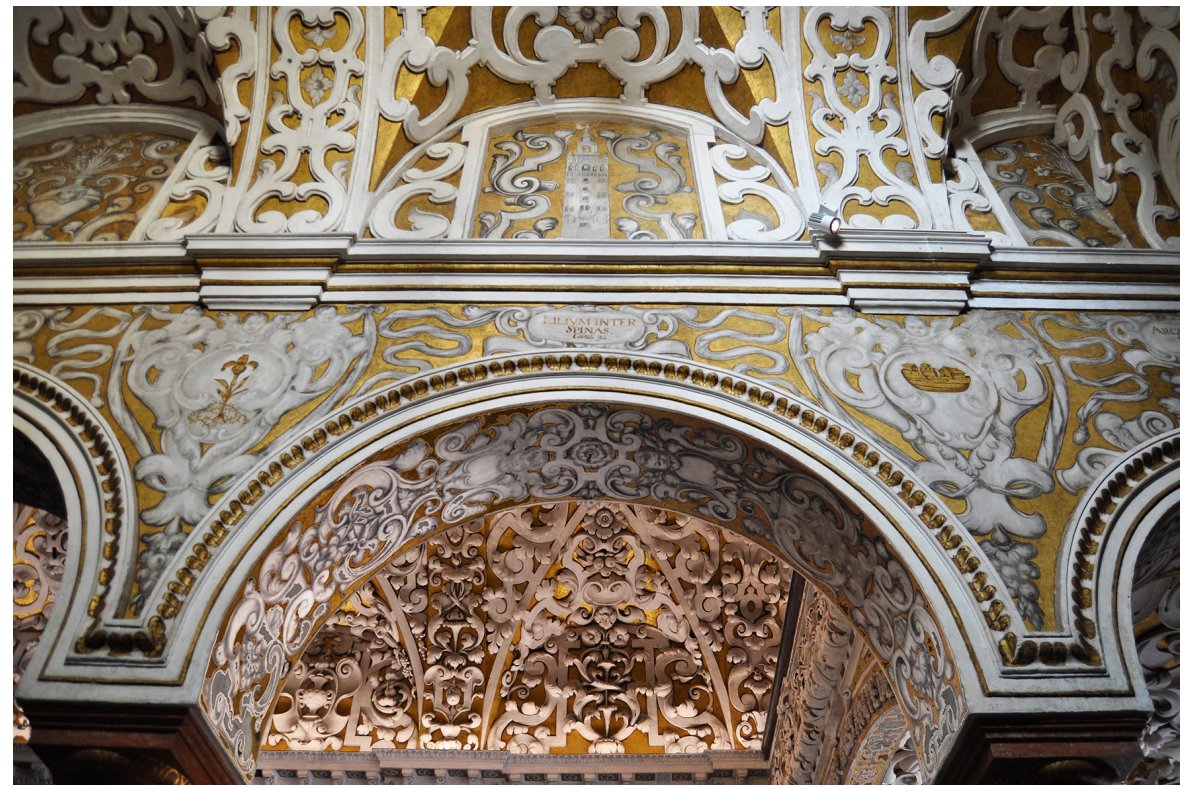




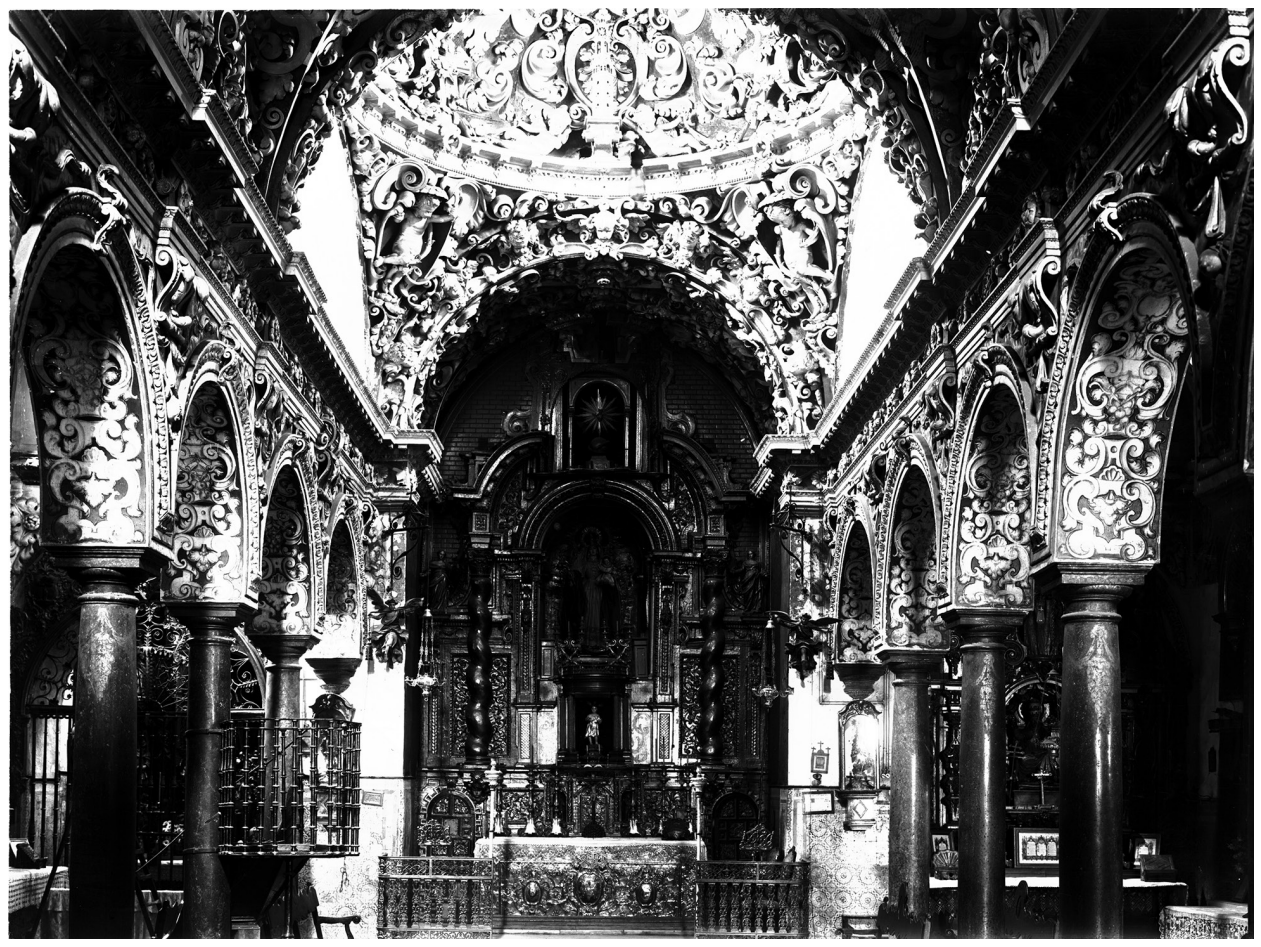

9. Interior del templo en 1919. Servicios Generales de Investigación, Fototeca Laboratorio de Arte, Universidad de Sevilla (SGI-FLA). No. R.: 4-184 (autor: José Barraca)

bandas textiles y labores auriculares, se desarrolla el programa de exaltación a la Virgen María, que alcanza su auténtico significado en los cuadros de Murillo, de La Inmaculada Concepción y de La Fe, situados en los testeros de las naves laterales (Hernández y Morales, 2020: 121-136). Se completan las paredes con un zócalo de azulejos atribuido a Diego de Sepúlveda (Falcón, 2015: 97). Para las bóvedas laterales se utilizaron labores de yeserías planas, de cartones recortados, que contrastan con la riqueza y volumetría de las guirnaldas, macollas frutales y florales, roleos y angelotes de la nave central. Tradicionalmente su diseño ha sido atribuido a Pedro Roldán y su ejecución a los hermanos Borja (Morales, 2010: 152-155). Unas y otras, destacadas sobre los fondos dorados, contribuyen a crear un espacio único, irreal y deslumbrante, en el que, en palabras de Bonet, «culminó y triunfó el Barroco» (1978: 67).

Tras la reforma, el templo pasó una década de tranquilidad absoluta, ya que en la documentación no existen anotaciones de obras de mantenimiento, iniciándose a partir de 1675. Estos trabajos se complicarían con el paso de los años y el envejecimiento de los materiales, obligando a intervenciones de mayor entidad y cuantía. Estas se podrían tipificar en el arreglo de tejados, reparación de armaduras, eliminación de goteras y de humedades que afectaban al ornato interior, siendo sucesivamente recompuestos ${ }^{25}$. Tales labores no suelen quedar individualizadas en la documentación, sino que se incluyen conjuntamente con otros de diversa índole o en las partidas de gastos de albañilería. De todas formas es interesante señalar que no solo se repararon las yeserías y los desconchados de las paredes, sino que también se contrató a pintores para dorar y estofar los fondos y enjalbegar o blanquear los motivos decorativos ${ }^{26}$. Estas labores se encuentran asociadas directamente a tareas de eliminación de polvo, deshollinado de las yeserías y limpieza de las paredes. En los siglos XVII y XVIII, estas se realizaban cada 6 o 10 años, aunque existen largos periodos en los que no se realizaron. La documentación no indica el perfil del personal encargado de efectuarlas, apuntándose ocasionalmente a peones, a «hombres» o a «deshollinadores» $y$, solo en una vez, en 1781, a José de Reina pero sin especificar su 
profesión. Las herramientas empleadas eran escobas de romero, escobones, escobas largas, bayetas y plumeros, que se ataban a cañas o a palos, o eran utilizados directamente al subirse los operarios en andamios o escaleras de mano. En no pocas ocasiones, como consecuencia de la limpieza, se producían importantes daños en las yeserías, teniéndose que contratar a continuación a maestros albañiles o a entalladores para su reintegración. Algunas veces, el polvo que ocasionaban estas intervenciones hacía necesario emplear a «mujeres por aljofifar la iglesia por lo que este sucio con el yeso que ha caído del entallado» ${ }^{27}$ [9].

En el siglo XIX, tras la promulgación de las leyes de desamortización del clero secular en 1837 y 1841, las tareas de reparación y mantenimiento se paralizaron, al perder el templo sus principales fuentes de ingresos. En 1863, la situación era alarmante, por lo que el párroco Juan Bautista Rodríguez solicitó al "gobernador del arzobispado» la intervención de la Junta de Reparación de Templos ${ }^{28}$. Fue el arquitecto Francisco de Paula Álvarez el autor del proyecto, señalando la urgencia de reparar el zócalo de azulejos y la pavimentación. El mal estado de los primeros se debía a intervenciones anteriores realizadas por «mano poco hábil», existiendo «muchos deterioros y alteración de su dibujo». La intervención propuesta era reducir la altura del zócalo de los $2,10 \mathrm{~m}$ originales a $1,50 \mathrm{~m}$ y colocar dos hiladas de piezas de color obscuro jaspeadas. Con la merma del zócalo se liberaban las piezas suficientes para sustituir las deterioradas y las que no correspondían a la decoración primitiva. En cuanto al suelo sería nivelado y pavimentado con losetas de barro cocido de la Fábrica de la Cartuja. Además, se proponía ampliar la plataforma del presbiterio ${ }^{29}$ y añadirle dos escalones de «mármol de Málaga», material utilizado también para los peldaños de las capillas. La obra del presbiterio se completaba con la colocación de una baranda de hierro colado con sus atriles. El presupuesto total se estimó en 19.623,24 reales $^{30}$.

El proyecto, enviado el 17 de agosto a la reina Isabel Il para ser financiado por el Estado, fue aprobado en 1865. Ese mismo año, la obra se adjudicó al contratista Vicente de Ayala y Muñoz. Sin embargo, los permisos del inicio de la obra se dilataron en la Corte y cuando se comprometió el dinero, el 10 de agosto de 1868, todo quedó paralizado al estallar la Revolución Gloriosa y el posterior Sexenio Democrático. En 1875 con la proclamación de Alfonso XII como

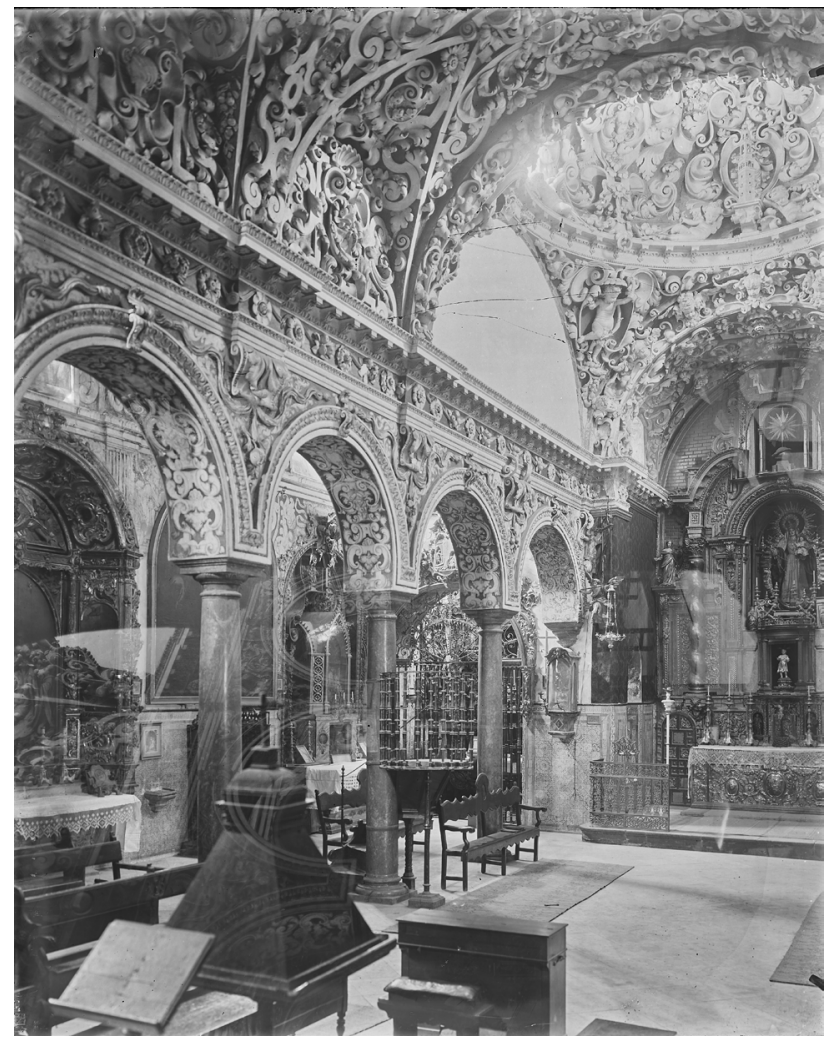

10. Interior del templo en 1925. SGI-FLA. № R.: 5-169 (autor: José María González-Nandin y Paúl)

rey de España, se fue volviendo a la normalidad, aunque la cuantía de la restauración no se liberó hasta septiembre de 1877. En esos momentos, se había hecho cargo de las obras el contratista Carlos Toledo Ladrón de Guevara, al renunciar Ayala en 1873. Las reparaciones se efectuarían en los años siguientes, pues el Ministerio de Gracia y Justicia las dio por finalizadas en mayo de $1880^{31}$. A pesar de tener constancia de su realización, no se siguió el proyecto de Álvarez, al menos en lo concerniente al zócalo. En las fotografías del templo de 1919 y 1925 no se observa diferencias en su altura, pues existiría un vacío de unos $60 \mathrm{~cm}$ entre la pintura y el zócalo, ni las hiladas jaspeadas ${ }^{32}$. En cambio, sí aparece la baranda del presbiterio, aunque colocada sobre un solo escalón, que sería eliminada en $1969^{33}$ [10].

La única restauración documentada en el siglo XX es la dirigida por Rafael Manzano Martos entre los años 1969 y 1972. Fue consecuencia del terremoto del 28 de febrero de 1969, de 7,3 grados de intensidad, que afectó a la estructu- 
ra del edificio. En ese mismo año, costeado por la Dirección General de Patrimonio Artístico y Cultural del Ministerio de Educación y Ciencia, se acomete una primera fase destinada a reparaciones de carácter general en el edifico, así como a la consolidación de ciertos elementos que se encontraban en peligro de desplome. En 1971 se inicia la segunda fase, saneando y renovando la armadura del crucero. Al año siguiente, se aborda la última centrada en la restauración de las yeserías de la nave ${ }^{34}$ y en la realización de las reproduc- ciones de los cuadros de Murillo de los lunetos de la media naranja, robados por el Mariscal Soult ${ }^{35}$. Con la restauración de las yeserías y las pinturas murales, en el 2015, concluían quince años de trabajos que han permitido devolver la belleza y el esplendor original al templo. Se trata de uno de los conjuntos monumentales más significativos e importantes del Barroco español, además de extraordinario ejemplo de la importancia del culto a la Inmaculada Concepción de María en la religiosidad sevillana.

\section{Notas}

1 Las obras de restauración se realizaron en tres etapas. En 2000 se remodelaron las dependencias parroquiales; entre 2010 y 2012 se intervino en la arquitectura del templo y durante 2014 y 2015 en su decoración mural. Esta última fue realizada por la empresa Ágora, Restauraciones de Arte, siendo dirigida por Juan Aguilar. La revalorización de la figura del canónigo Neve se realizó en 2012 con la exposición Murillo y Justino de Neve. El arte de la amistad en Madrid, Sevilla y Londres.

2 Publicada por López (2012) y Gil (2013a; 2013b; 2015) fue asumida por Falcón (2015).

3 Falcón señala que la ampliación pudo realizarse en tiempos de Yusuf Pichón, nombrado en 1369 Contador Mayor por Enrique II (2015: 65).

4 Agradezco a mi amigo y compañero Manuel Gámez Casado la realización de las fotografías.

5 La espadaña fue remodelada en 1651, obra atribuida a Falconete, y, posteriormente, en 1741 (Falcón, 2012: 126; 2015: 74; Aguilar y Arenillas, 1996: 40; Cruz, 1997: 84; Arenillas, 2005: 176, 234).

6 Hacia 1760, coincidiendo con la donación de la imagen del santo titular y la creación de su hermandad (Falcón, 2015: 84, 118-120), se le dio la configuración actual, construyéndose el retablo, la embocadura de la portada y las yeserías de su cúpula. Estas fueron atribuidas a Pedro Roldán, a pesar de la presencia de rocallas. Aunque los niños copian las actitudes de los existentes en las pechinas de la media naranja de la nave central, su realización se asemeja a los que ornamentan la fachada de la iglesia de San Juan de Dios, antiguo Hospital de Nuestra Señora de la Paz, concluida en 1759 (Delgado, 2019: 49-50).

7 Anterior a 1625 solo se ha localizado unos arreglos del tejado, Archivo Catedral de Sevilla (ACS). Fábrica. Libros de visitas. 1566-1574. Leg. 05250, s/f., y otros, en 1620, en la capilla mayor. Para esta se compraron diferentes materiales que costaron 480 reales. A.C.S. Fábrica. Libramientos ordinarios de Cabildo. Leg. 6318. S/f. Agradecemos a Alfredo J. Morales dicha información.

8 ACS. Secretaría. Actas Capitulares. 1624-1625. Leg. 52, ff. 97, 97v; Fondo Histórico. Caja. 07126: nº 36.

9 Archivo Parroquial de San Nicolás (APSN). Fondo de Santa María la Blanca (FSMB). Libro de la Cofradía del Pópulo, 1630-1732.

10 Para Cruz la primera obra en el templo de Falconete fue la capilla bautismal en 1642 (1997: 84). ACS, Fábrica. Libros de visitas. 1633-1646. Leg. 05251, ff. $13 \mathrm{v}, 69 \mathrm{v}-70$.

11 Ibidem, ff. 14, 68, 69v-71v, 72, 221v, 294, 367. 415-416; leg. 05253: 1648-1666: ff. 129; 392v, 445.

12 Ibid., leg. 05251: 1633-1646: ff. 13v, 72v, 222, 224v, 294v.

13 Ibid., ff. 14,70 .

14 ACS. Secretaría. Actas Capitulares. 1641-1642. Leg. 57: f. 299. De estos, 28.050 maravedís se entregaron el 1 de octubre de 1642. Ibid., Fábrica. Libramientos ordinarios de Cabildo. 1641-1644. Leg. 6323. Fol. 114. APSN. FSMB. Libro de descargo de la Hermandad del Pópulo. Papel suelto.

15 ACS. Fábrica. Libro de visitas. 1566-1574. Leg. 05250, f. 1-2.

16 Otras intervenciones en la capilla son, en 1655, la realización del pie de la pila bautismal por Hernando de Castro y en 1721 el arreglo de un desconchado. Ibid., Leg. 05253: 1648-1666, f. 333; leg. 05268: 1717-1722, f. 322.

17 La reja fue realizada por un «herrero de San Roque», costando 811 reales y 17 maravedís con el dorado. En 1800 fue reparada por el «herrero Ponce». Idem., Leg. 05270: 1723-1796, s/f.; leg. 05281: 1797-1800, f. 376v-377; leg. 05282: 1801-1803, f. 149-149v.

18 Falcón no señala en qué documentación basa tales afirmaciones. Gil (2015: 232-233) también aboga por la existencia de este espacio, aunque se fundamenta en la descripción que de la «capilla» de san Pedro realiza González de León, quien señala que «tiene su reja» (1844/1973: 103). La reja posiblemente era una baranda de comulgatorio, similar a la que aún se conserva en la capilla Sacramental del siglo XVIII.

19 APSN. FSMB. Libro de Actas de la Hermandad Sacramental, Ánimas benditas del Purgatorio... comienzan en 1696... Cabildo de 3 de julio de 1758, f. 134 v. 20 Ibid., f. 88v.

21 ACS. Fábrica. Libro de visitas.1648-1666. Leg. 05253, f. 267.

22 APSN. FSMB. Libro de Actas de la Hermandad Sacramental. Cabildo de 23 de agosto de 1734, ff. 112v, 131.

23 Según la inscripción del retablo de la Piedad, este fue renovado en 1774 y se le añadieron las rocallas. Por las mismas fechas también se modernizaría el retablo del Sagrado Corazón, cuya estructura original, de mediados del XVII, alberga figuras en relieve de estética de Juan de Mesa. Su calle central fue modificada en el siglo XX.

24 ACS. Secretaría. Actas Capitulares. 1661-1662. Leg. 66, ff. 5v, 38v, 39v. 
25 Existe un amplio registro de estos trabajos. A.C.S. Fábrica. Libros de visitas. 1675-1841.

26 Ibid., Libros de visitas. 1701-1814.

27 Ibid., Libros de visitas. 1701-1806. Otras reparaciones se efectuaron en vidrieras, basas de las columnas y zócalos de azulejos. Ibid., Libros de visitas. 16791776.

28 En la misiva, firmada con Juan José García, alcalde la ciudad, se decía que «se encuentra su fábrica y adorno en gran deterioro sobresaliendo el pavimento que se halla desnivelado, irregular y defectuoso... la urgencia de resanar el estofado y alicatado de la Iglesia, así como los notables defectos en su solería". Archivo General del Arzobispado de Sevilla (AGAS). Administración General. Reconstrucción de templos. Expediente 17.567: n. 6. Obras en Santa María la Blanca. 1863-1879. Carta 1/06/1863.

29 Según Falcón, la capilla mayor era en origen poligonal, aunque su aspecto actual corresponde a la remodelación de 1657 (1988: 122; 2015: 75-76). Durante la restauración del 2010 se descubrió, tras el retablo, un espacio cubierto con una media naranja ovalada (Gil, 2015: 236), cuyas características hacen sospechar en una intervención a fines del siglo XVI.

30 AGAS. Administración General. Reconstrucción de templos. Expediente 17.567: n. ${ }^{\circ}$ 6. Obras en Santa María la Blanca. 1863-1879. Proyecto y pliegos de condiciones. 28/07/1863.

$31 \mathrm{lbid}$. El 11 de ese mes se libraron las últimas 3.805 pesetas que faltaban por pagar, tras dos pagos de 100 y 1000 pesetas realizados en fechas anteriores sin especificar. El total de la obra ascendió a 19.620 reales.

32 El aspecto actual se debe a la intervención del 2012, realizada por el restaurador Carlos Núñez.

33 En esas obras también se quitaría el púlpito de hierro, con escalera de madera, realizado por el rejero Marcos de la Cruz en 1657. A.C.S. Libro de Visitas. 1648-1666. Leg. 5253, fol. 392.

34 La tradición oral señala una intervención en las yeserías tras finalizar la Guerra Civil.

35 Aunque los originales fueron devueltos a España, quedaron en el Museo del Prado. Archivo Central de Cultura. Dirección General de Bellas Artes (ACC-DG-

BA). Proyectos de restauración. Cajas: 70.686; 70.869 y 71.133.

\section{Bibliografía}

AGUILAR GUTIÉRREZ, Juan y ARENILLAS, Juan Antonio (1996), «Las pinturas murales de la fachada de la iglesia de Santa María la Blanca y su restauración», Atrio, n. ${ }^{\circ}$ 8/9, pp. 37-51.

ARENILLAS, Juan Antonio (2005), Del Clasicismo al Barroco: Arquitectura Sevillana del siglo XVII, Diputación de Sevilla, Sevilla.

BONET CORREA, Antonio (1978), Andalucía Barroca, Polígrafa, Barcelona.

CÓMEZ, Rafael (2015), Sinagogas de Sevilla, Diputación de Sevilla, Sevilla.

CORRAL SÁNCHEZ, Nuria (2014), «El pogromo de 1391 en las Crónicas de Pero López de Ayala», Ab Initio: Revista digital para estudiantes de Historia, n. ${ }^{\circ}$ 10, pp. 61-75.

CRUZ ISIDORO, Fernando (1997), Arquitectura sevillana del siglo XVII: maestros mayores de la Catedral y del Concejo hispalense, Universidad de Sevilla, Sevilla.

DELGADO ABOZA, Francisco Manuel (2019), La iglesia de Nuestra Señora de la Paz: Orden de San Juan de Dios, Diputación de Sevilla, Sevilla.

FALCÓN MÁRQUEZ, Teodoro (1988), «La iglesia de Santa María la Blanca», Laboratorio de Arte, n. 1, pp. 117-131.

FALCÓN MÁRQUEZ, Teodoro (2011), «El canónigo Justino de Neve en la Iglesia de Santa María la Blanca», Laboratorio de Arte, n. ${ }^{\circ} 23$, pp. 589-598.

FALCÓN MÁRQUEZ, Teodoro (2012), «La iglesia de Santa María la Blanca, punto de encuentro entre Murillo y Justino de Neve», en FINAL-

DI, Gabriele (ed.), Murillo y Justino de Neve, el arte de la amistad, Museo Nacional del Prado, Fundación Focus-Abengoa, Dulwich Picture Gallery, Madrid, pp. 61-71.

FALCÓN MÁRQUEZ, Teodoro (2013a), «Retablos y esculturas de la iglesia de Santa María la Blanca», Laboratorio de Arte, n. ${ }^{\circ}$ 25, pp. 301-320.

FALCÓN MÁRQUEZ, Teodoro (2013b), «Pinturas murales y en lienzo de la Iglesia de Santa María la Blanca de Sevilla», en ZALAMA RODRÍ-

GUEZ, Miguel Ángel, MOGOLLÓN CANO CORTÉS, Pilar y ANDRÉS ORDAX, Salvador (coords.), Alma Ars. Estudio de Arte e Historia en homenaje al Dr. Salvador Andrés Ordax, Universidad de Valladolid, Valladolid, pp. 265-272.

FALCÓN MÁRQUEZ, Teodoro (2015), La Iglesia de Santa María la Blanca y su entorno, Universidad de Sevilla, Sevilla.

FALCÓN MÁRQUEZ, Teodoro (2017), «Santa María la Blanca, un milagro barroco: contribución de Murillo y Neve a su patrimonio monumental y artístico", en BELTRÁN MARTíNEZ, Lidia y QUILES GARCÍA, Fernando (coords.), Cartografía murillesca: Ios pasos contados, Universidad Pablo de Olavide, Sevilla, pp. 94-11. 
GIL DELGADO, Óscar (2013a), «Una Sinagoga desvelada en Sevilla; estudio arquitectónico», Sefarad, n. 1, pp. 69-96.

GIL DELGADO, Óscar (2013b), "Santa María la Blanca de Sevilla: templo de tres religiones. Estudio arquitectónico», Archivo Hispalense, n. ${ }^{\circ}$ 291-293, pp. 65-97.

GIL DELGADO, Óscar (2015), Arquitectura de Santa María la Blanca: mezquita, sinagoga e iglesia en Sevilla, Universidad de Sevilla e Instituto Universitario de Arquitectura y Ciencias de la Construcción, Sevilla.

GONZÁLEZ DE LEÓN, Félix (1844/1973), Noticia artística, histórica y curiosa de todos los edificios públicos, sagrados y profanos de esta muy noble, muy leal, muy heroica e invicta ciudad de Sevilla, José Hidalgo, Sevilla. Reed., Gráficas del Sur, Sevilla.

HERNÁNDEZ-NÚÑEZ, Juan Carlos y MORALES, Alfredo J. (2020), «Un programa de exaltación mariana en la iglesia de santa María la Blanca de Sevilla", Imago. Revista de Emblemática y Cultura Visual, n. ${ }^{\circ}$ 12, pp. 121-136. https://dx.doi.org/10.7203/imago.12.17787.

LÓPEZ LETAMENDÍA, José Enrique (2012), «Santa María la Blanca: el templo de las tres religiones», Aparejadores, n. ${ }^{\circ}$ 81, pp. $32-48$.

MORALES, Alfredo J. (2010), La piel de la arquitectura: yeserías sevillanas de los siglos XVII y XVIII, Diputación de Sevilla, Sevilla.

NúÑ̃EZ CASARES, Lourdes y otros (2000), «Intervención de la pintura "La Cena” de Bartolomé Esteban Murillo», Boletín PH, n. 32, pp. 107-210.

PONZ, Antonio (1786/1988), Viage de España, tomo IX, Viuda de Ibarra, Hijos y compañía, Madrid. Reed, vol. 3, Aguilar, Madrid.

TORRE FARFÁN, Fernando de la (1666), Fiestas que celebro la iglesia parrochial de Santa María la Blanca, capilla de la Santa Iglesia Metropolitana y Patriarchal de Sevilla, en obsequio del nuevo Brebe concedido por Nuestro Santísimo Padre Alexandro VII a favor del purísimo Mysterio de la Concepcion sin culpa Original de Maria Santísima Nuestra Señora en el primero instante physico de su ser, Juan Gómez Blas, Sevilla.

VALDIVIESO, Enrique y MARTÍNEZ DEL VALLE, Gonzalo (2012), Recuperación visual del patrimonio perdido: conjuntos desaparecidos de la pintura sevillana de los Siglos de Oro, Universidad de Sevilla, Sevilla. 